\title{
Acceptance of human papillomavirus (HPV) vaccination among young women in a country with a high prevalence of HPV infection
}

\author{
SUSANNA ALDER ${ }^{1}$, CLAUDIA PERINETTI $^{2}$, MIRIAM MINTS $^{1}$, KAREN BELKIĆ $^{3}$, KARIN SUNDSTRÖM $^{4}$, \\ SVEN SANDIN $^{4}$, ELISABETE WEIDERPASS ${ }^{5-7}$ and SONIA ANDERSSON ${ }^{1}$
}

${ }^{1}$ Department of Women's and Children's Health, Division of Obstetrics and Gynecology, Karolinska Institutet and Hospital, 17176 Stockholm, Sweden; ${ }^{2}$ Department of Obstetrics and Gynecology, Docent Extention Universidad Nacional de Cuyo, Regional Hospital Diego Paroissien, Godoy Cruz 475, Maipú, Mendoza, Argentina; ${ }^{3}$ Institute of Oncology-Pathology, Karolinska Institutet and Hospital, 17176 Stockholm; ${ }^{4}$ Department of Medical Epidemiology and Biostatistics Karolinska Institutet, 17177 Stockholm, Sweden; ${ }^{5}$ Cancer Registry of Norway, Majorstuen, 0304, Oslo; ${ }^{6}$ Department of Community Medicine, 9037, Universitetet I Tromso, Tromso, Norway; ${ }^{7}$ Samfundet Folkhälsan, Genetic Epidemiology Group,

Folkhälsan Research Center, Biomedicum 1, FI-00014 University of Helsinki, Helsinki, Finland

Received April 16, 2013; Accepted June 4, 2013

DOI: $10.3892 / \mathrm{ijo} .2013 .2023$

\begin{abstract}
Cervical cancer is the second most common cancer among women in Argentina and the mortality has remained unchanged for the last 30 years. The 2011 national implementation of human papillomavirus (HPV) vaccination will be a key component of future cervical cancer prevention. Vaccination of young adult women is not included in the program, although these women could also benefit from the vaccine, especially in underserved areas with a high prevalence of HPV. However, research on acceptance of HPV vaccination within this group is scarce. The aim of this study was to investigate acceptance of HPV vaccination, the correlation between acceptance and cost, as well as other factors and perceptions of HPV vaccination among young adult women in Argentina. In total, 174 young women aged 18-30 years were included in this quantitative cross-sectional hospital-based study in a low resource area of the Mendoza Province, conducted through structured questionnaire-based interviews. Multinomial logistic regression models were used to investigate correlates of acceptance. Acceptance of HPV vaccination was high if it was free $(95 \%)$ and even if it was not $(75 \%)$. A significant positive association was found between acceptance and belief in vaccine safety $(\mathrm{p}=0.01)$ and between acceptance and not
\end{abstract}

Correspondence to: Dr Sonia Andersson, Department of Women's and Children's Health, Division of Obstetrics and Gynecology, Karolinska Institutet, Elevhemmet H2:00, Karolinska University Hospital Solna, 17176 Stockholm, Sweden

E-mail: sonia.andersson@karolinska.se

Key words: acceptance, adults, Argentina, HPV vaccination, knowledge being a welfare recipient $(\mathrm{p}=0.00)$. Nearly half the participants incorrectly believed that they would be fully protected against cervical cancer after vaccination. Our findings suggest that acceptance of HPV vaccination is high among young women in a high-risk, relatively underserved area, even if vaccination is not free. Extensive misconceptions about the vaccine, however, highlight the need for further education about HPV vaccination.

\section{Introduction}

Cervical cancer is a major health problem and the third most common cancer among women worldwide, with 530,000 new cases and 275,000 deaths in 2008 (1). The global burden of cervical cancer varies considerably and $>85 \%$ of all cases occur in less-developed regions of the world (1). Also, prevalence is high among younger women, rising rapidly after the age of 30 years (2). However, cervical cancer is preventable due to its etiology, which is attributed to human papillomavirus (HPV) infection (3) and through screening for the early detection of precancerous lesions (4). The recent introduction of primary prevention by HPV vaccination offers the possibility to greatly reduce the global cervical cancer burden, particularly in regions with insufficient screening coverage (5). The preferred strategy is that HPV vaccination be introduced as part of a coordinated program for cervical cancer prevention (6).

There are currently two prophylactic vaccines available. Both include HPV16 and 18 (7), which account for $70 \%$ of all invasive cervical cancer (8). A recent meta-analysis of randomized-controlled trials found these vaccines to be well-tolerated and safe and to provide high levels of protection against persistent HPV infection and cervical disease associated with HPV vaccine types, although the need for trials addressing longer-term safety and efficacy was noted (7). The American Academy of Pediatrics recommends routine 
vaccination for girls aged 11-12 years with 3 doses of the quadrivalent or bivalent vaccine and catch-up vaccination for females aged 13-26 years (9).

The burden of cervical cancer is particularly heavy in Latin America, where $\sim 68,500$ new cases were reported in 2008 and where mortality rates remain high $(6,10)$. In Argentina, cervical cancer is the second most common female cancer, despite more than 30 years of opportunistic Pap smear screening, frequently beginning at relatively young age (10). Women living in provinces with a lower socioeconomic level are reported to be particularly afflicted by cervical cancer and HPV prevalence among these women is high (11). A meta-analysis found the general HPV prevalence in South America to be $13 \%$ among cytological normal women, with the specific prevalence in Argentina ranging from 15-46\% (12). In 2011, Argentina initiated free HPV vaccination of 11-year-old Argentinean girls (13). There is no subsidized catch-up vaccination for young adult women and vaccination outside the vaccination program of young girls is limited to the private sector (14). It has been estimated that $74 \%$ of all cervical cancer and precancerous lesions in Argentina could be avoided if HPV vaccination were to be used as primary prevention (15).

A recently published study on vaccination acceptance from the capital city Buenos Aires reported a high acceptance of HPV vaccination among the 1,200 women included (16). However, to our knowledge, there have not been any published studies on acceptance of HPV vaccination in other areas of the country. Since the populations outside the capital have a particularly high risk of cervical cancer and HPV infection, such investigations are urgently needed.

Therefore, the present study was undertaken to examine acceptance of HPV vaccination among young Argentinean women living in a non-metropolitan, low-income region of Argentina and the correlation of this acceptance with cost. We also investigated women's perceptions of HPV vaccination to better understand possible behavioral changes after vaccination and examined the awareness of HPV-associated disease and future theoretical screening practices.

\section{Materials and methods}

Study design and data collection. This quantitative crosssectional hospital-based study was conducted through structured questionnaire-based interviews and written questionnaires at the Diego Paroissien Public Hospital in Maipú, Mendoza Province, Argentina. Between September and October 2011, a consecutive sample of 228 women attending the Obstetrics/Gynecology Ward and the Outpatient Gynecology Clinic of the hospital were invited to participate in the study. To be eligible, women had to be 18-30 years of age and have no known cervical malignancy or acute medical condition. One of the authors (S. Alder) conducted all interviews.

The questionnaire was based on and was virtually identical to one used in a recent nationwide population-based survey on the acceptance of HPV vaccination in Sweden (17). Minor modifications were made before and after a pilot trial aimed at adapting the questionnaire to the Argentinean population. The questionnaire contained a total of 54 questions divided into six sections: demographics (part 1), sexual behavior (part 2), awareness of HPV-associated disease (part 3), general perception of vaccination (part 4), acceptance of HPV vaccination (part 5) and screening practices (part 6). As in the Swedish study, the causative role of HPV in cervical cancer development was explained to the participants before they answered questions on HPV vaccination acceptance, but after answering questions on awareness.

Ethical clearance was received from the Ethics Review Committee of the Diego Paroissien Public Hospital. The purpose of the study was explained to all potential participants and all those who agreed to take part gave oral consent prior to participation.

Statistical methods. The basic characteristics and frequency distribution of the pre-coded variables were calculated using SPSS, IBM version 20.0. Acceptance of HPV vaccination (the outcome variable) was categorized into: i) unsure/unwilling to vaccinate, even if vaccination was free, ii) willing only if vaccination was free, iii) willing even if vaccination was not free. Associations between each of the independent variables and acceptance of HPV vaccination were assessed fitting multinomial cumulative logistic regression models using SAS $^{\circledR}$, System 9.1 and estimating odds ratios (OR) with associated $95 \%$ confidence intervals (Table III). Unsure/unwilling to vaccinate, even if vaccination was free, was set as the reference category. The frequencies of some outcomes were too low for multinomial regression analysis to fit and in these cases, exact estimates and p-values were obtained. For each independent variable where the omnibus p-value was $<0.05$, multivariable regression models were also fitted including all other covariates where the $p$-value was $<0.05$ with the dependent variable (Table IV). All p-values were two-sided and based on the Wald-Chi-square test and p-values $<0.05$ were considered statistically significant.

\section{Results}

Basic characteristics. Of the 228 women invited to participate, $200(88 \%)$ agreed. One hundred and seventy-four women $(87 \%)$ were administered the questionnaire-based interview, while $26(13 \%)$ completed the written questionnaire independently. However, due to the poor quality (predominantly missing data) of the responses in the written questionnaires, all data obtained by that method were excluded. Thus, the final study population was comprised of the 174 (76\%) women from whom data had been obtained exclusively by interview.

Median age of the study population was 23 years and $84 \%$ were married or in a relationship; $71 \%$ were housewives/unemployed and half had an annual income of $<170$ Euro. Almost two-thirds of the study participants were welfare recipients and had less than a high school education (Table I).

Acceptance of HPV vaccination. Altogether, 95\% of participants stated that they would be willing to be vaccinated against HPV: three of four were willing to be vaccinated even if vaccination was not free and $20 \%$ were willing only if vaccination was free (Table II). Among those willing to pay for HPV vaccination, the 10-90th percentile ranges for the acceptable price cited was 3.20-49.17 Euro per dose, with a median of 11.50 Euro (data not shown). 
Table I. Demographic characteristics of the 174 participating women attending the Obstetrics/Gynecology Ward and Outpatient Gynecology Clinic of the Diego Paroissien Public Hospital, Mendoza Province, Argentina.

\begin{tabular}{|c|c|c|}
\hline & $\mathrm{n}$ & $\%$ \\
\hline Median age (years) & 23 & \\
\hline \multicolumn{3}{|l|}{ Age (years) } \\
\hline $18-19$ & 31 & 17.8 \\
\hline $20-25$ & 92 & 52.9 \\
\hline $26-30$ & 51 & 29.3 \\
\hline \multicolumn{3}{|l|}{ Education level } \\
\hline$<$ High school & 113 & 64.9 \\
\hline High school & 38 & 21.8 \\
\hline$>$ High school & 23 & 13.2 \\
\hline \multicolumn{3}{|l|}{ Household on welfare } \\
\hline No & 68 & 39.1 \\
\hline Yes & 106 & 60.9 \\
\hline \multicolumn{3}{|l|}{ Annual income (Euro) } \\
\hline <170 (1st quartile) & 85 & 49.7 \\
\hline 170-330 (2nd quartile) & 13 & 7.6 \\
\hline 330-490 (3rd quartile) & 36 & 21.1 \\
\hline$>490$ (4th quartile) & 37 & 21.7 \\
\hline \multicolumn{3}{|l|}{ Occupation } \\
\hline Full-time employee & 13 & 7.5 \\
\hline Part-time employee & 15 & 8.6 \\
\hline Housewife/unemployed & 124 & 71.3 \\
\hline Student & 22 & 12.6 \\
\hline \multicolumn{3}{|l|}{ Marital status } \\
\hline Married/in a relationship & 146 & 83.9 \\
\hline Single & 28 & 16.1 \\
\hline
\end{tabular}

Other correlates of acceptance. A statistically significant positive association was found between a woman's belief in the safety of vaccination in general and willingness to be vaccinated (Table IV). Uncertainty or lack of confidence in vaccine safety in general was associated with lower acceptance, regardless of cost. However, women who believed vaccination to be unsafe were even less willing to be vaccinated for free (OR: 0.07, 95\% CI: 0.01-0.49), while those who were unsure were less willing to be vaccinated if out-of-pocket payment was required (OR: 0.05, 95\% CI: 0.01-0.51). An inverse association in terms of $\mathrm{p}$-values was also found between women who were welfare recipients and acceptance of vaccination if out-ofpocket payment was required (OR: 0.11, 95\% CI: 0.01-0.99), as well as an association between having heard of condyloma prior to the study and vaccination acceptance, though confidence intervals here were wide. Also, an association between belief in vaccine effectiveness and acceptance of HPV vacci-
Table II. Theoretical acceptance of human papillomavirus (HPV) vaccination in relation to cost.

$\mathrm{n}$

$\%$

Would you like to be vaccinated against HPV?

Unsure/unwilling, even if vaccination 9 5.2 was free (total) $)^{\mathrm{a}, \mathrm{b}}$

Willing only if vaccination was free

Willing even if vaccination was not free

ansure: $n=5$ (2.9\%). ${ }^{\mathrm{b}}$ Unwilling: $\mathrm{n}=4$ (2.3\%).

nation was shown in the univarate model (Table III), although it did not sustain statistical significance in the multivariable analysis.

Perceptions of HPV vaccination. The majority of the women $(63 \%)$ stated that age 14 years or below was the preferred age to initiate HPV vaccination (Table V). Nearly half the women incorrectly believed that HPV vaccination would offer complete protection against cervical cancer, while only $29 \%$ knew it would not. Three of four women would not consider having unsafe sex more often after HPV vaccination, while $10 \%$ stated they would. Three out of four previously screened women stated that they would continue to participate in screening at the same rate, while one-quarter stated that they would participate less frequently. Meanwhile, the majority of non-screened participants expressed a desire to undergo screening in the future; only $4 \%$ did not. Concern about possible side-effects was the main reason for abstaining from HPV vaccination, followed by concern about its protective effect.

Knowledge and previous screening participation. The majority of the participants had heard of cervical cancer prior to the study, over half had heard of HPV and almost one-quarter had heard of condyloma (Table VI). The highest awareness was for cervical cancer screening, which almost all respondents had heard about. Just over half of the women had participated in screening at some point in their life and the participation rate increased with age. Less than one-third of women aged 18-19 years had participated in screening, while half of women aged 20-25 years and 84\% of women aged 26-30 years had participated.

\section{Discussion}

This is one of the few studies on acceptance of HPV vaccination from Argentina and the first from a non-metropolitan region of the country. The comprehensive questionnaire addressed several aspects of vaccination acceptance and also investigated the potential for change in future health-related behavior after vaccination. Additionally, important data on current screening practices among study women were obtained, which is yet another relatively unstudied parameter in Argentina. 
Table III. Theoretical acceptance of human papillomavirus (HPV) vaccination with 'Unsure/unwilling even if vaccination was free' as the reference category.

\begin{tabular}{|c|c|c|c|c|c|c|c|c|c|}
\hline \multirow[b]{2}{*}{$\begin{array}{c}\text { No. of } \\
\text { subjects in } \\
\text { analysis }\end{array}$} & \multicolumn{4}{|c|}{$\begin{array}{c}\text { Willing only if vaccination } \\
\text { was free }\end{array}$} & \multicolumn{4}{|c|}{$\begin{array}{l}\text { Willing even if vaccination } \\
\text { was not free }\end{array}$} & \multirow[b]{2}{*}{ p-value } \\
\hline & $\mathrm{n}$ & $\%$ & OR & $95 \% \mathrm{CI}$ & $\mathrm{n}$ & $\%$ & OR & $95 \% \mathrm{CI}$ & \\
\hline
\end{tabular}

Age (years)

$18-19$

20-25

26-30

Education level

$<$ High school

High school

$>$ High school

Marital status ${ }^{\mathrm{a}}$

Married/in a relationship

Single

Welfare recipient

No

Yes

Disposable income (Euro/year) ${ }^{\mathrm{a}}$

$<170$ (1st quartile)

170-330 (2nd quartile)

330-490 (3rd quartile)

$>490$ (4th quartile)

Believes vaccination to be an

effective way to prevent disease

Very or fairly effective

Not so effective or not effective

Don't know

13

27

Believes vaccination to be a safe method to prevent disease

$$
\begin{array}{lll}
24 & 18.5 & 1
\end{array}
$$

$\begin{array}{ll}5 & 18.5\end{array}$

$5 \quad 29.5$

$$
0.10 \quad 0.02-0.73
$$

$0.14 \quad 0.02-1.06$

18

80.0

66.7

$9 \quad 52.9$

$\begin{array}{lll}61 & 89.7 & 1\end{array}$

$\begin{array}{llll}70 & 66.0 & 0.14 & 0.02-1.18\end{array}$

$\begin{array}{cccc}23 & 74.2 & 1 & \\ 21 & 72.8 & 0.73 & 0.08-6.85 \\ 41 & 80.4 & 0.45 & 0.05-4.23\end{array}$

0.49

$110 \quad 75.3$

$21 \quad 75.0 \quad 2.32 \quad 0.35-\infty$

0.40

$69.2 \quad 0.19 \quad 0.00-1.27$
Very or fairly safe

Not so safe or not safe

Don't know

119

41

Heard of HPV prior to study

No

Yes

Heard of condyloma (genital warts)

prior to study ${ }^{\mathrm{a}}$

Yes

No

$\begin{array}{lll}39 & 95.1 & 1\end{array}$

0.00

$24 \quad 20.2 \quad 1$

$4 \quad 9.8$

$\begin{array}{ll}6 & 42.9\end{array}$

0.07 0.01-0.47

$0.25 \quad 0.03-2.16$

93

32

6

78.0

78.0

42.9

$0.14 \quad 0.03-0.75$

$0.07 \quad 0.01-0.54$

$\begin{array}{lll}53 & 71.6 & 1\end{array}$

$\begin{array}{llll}78 & 78.0 & 1.18 & 0.30-4.59\end{array}$

0.60

Heard of cervical cancer prior

to study

Yes $\begin{array}{lll}26 & 18.4 & 1\end{array}$

$\begin{array}{lll}8 & 24.2 & 2.46\end{array}$
$.55 \quad 0.00-20.77$

92

0.01

No 
Table III. Continued.

\begin{tabular}{|c|c|c|c|c|c|c|c|c|c|}
\hline \multirow[b]{2}{*}{$\begin{array}{l}\text { No. of } \\
\text { subjects in } \\
\text { analysis }\end{array}$} & \multicolumn{4}{|c|}{$\begin{array}{l}\text { Willing only if vaccination } \\
\text { was free }\end{array}$} & \multicolumn{4}{|c|}{$\begin{array}{l}\text { Willing even if vaccination } \\
\text { was not free }\end{array}$} & \multirow[b]{2}{*}{$\mathrm{p}$-value } \\
\hline & $\mathrm{n}$ & $\%$ & OR & $95 \% \mathrm{CI}$ & $\mathrm{n}$ & $\%$ & OR & $95 \% \mathrm{CI}$ & \\
\hline
\end{tabular}

Lifetime sexual behavior ${ }^{\mathrm{a}}$

Only heterosexual contacts

Only homosexual contacts

Bisexual contacts

Never had sex

$\begin{array}{rrrrr}170 & 34 & 20.0 & 1 & \\ 0 & 0 & 0.0 & - & - \\ 1 & 0 & 0.0 & - & - \\ 3 & 0 & 0.0 & - & -\end{array}$

$\begin{array}{rrcc}127 & 74.7 & 1 & \\ 0 & 0.0 & - & - \\ 1 & 100.0 & 0.07 & 0.01-\infty \\ 3 & 100.0 & 0.26 & 00.3-\infty\end{array}$

Self-perceived risk of

contracting $\mathrm{STI}^{\mathrm{a}, \mathrm{b}}$

No or low risk

Fairly high or high risk

Don't know

$\begin{array}{rrrcc}149 & 29 & 19.5 & 1 & \\ 12 & 3 & 25.0 & 1.12 & 0.11-\infty \\ 10 & 2 & 20.0 & 0.71 & 0.05-\infty\end{array}$

$\begin{array}{lll}111 & 74.5 & 1\end{array}$

0.98

$\begin{array}{llll}9 & 75.0 & 0.97 & 0.13-\infty\end{array}$

Anal sex ever ${ }^{\mathrm{b}}$

No

139

$\begin{array}{lll}27 & 19.4 \quad 1\end{array}$

$\begin{array}{llll}8 & 80.0 & 0.86 & 0.17-\infty\end{array}$

Yes

32

$\begin{array}{llll}7 & 21.9 & 0.91 & 0.15-5.37\end{array}$

$105 \quad 75.5 \quad 1$

0.91

Oral sex ever ${ }^{\mathrm{b}}$

No

133

$\begin{array}{lll}27 & 20.3 & 1\end{array}$

23

71.

$0.77 \quad 0.15-3.93$

Yes

$\begin{array}{lll}98 & 73.7 & 1\end{array}$

0.68

Vaginal sex only ${ }^{\mathrm{b}}$

No

$\begin{array}{llll}53 & 10 & 18.9 & 1\end{array}$

118

24

20.3

Yes

Below median age $(\leq 16)$

$$
14 \quad 19.4
$$

$57 \quad 79.2$

Number of sexual partners in past year ${ }^{\mathrm{a}, \mathrm{b}}$

Median number or below (0-1)

$\begin{array}{rrrcrrcrrr}150 & 28 & 18.7 & 1 & & 113 & 75.3 & 1 & & 0.38 \\ 21 & 6 & 28.6 & 2.44 & 0.31-\infty & 15 & 71.4 & 1.61 & 0.23-\infty & \end{array}$

Condom use with temporary sexual partners in past year ${ }^{\mathrm{a}, \mathrm{b}}$

\begin{tabular}{|c|c|c|c|c|c|c|c|c|c|c|}
\hline Always or almost always (75-100\%) & 10 & 3 & 30.0 & 1 & & 7 & 70.0 & 1 & & 0.41 \\
\hline Less frequently ( $<75 \%$ of the time) & 6 & 2 & 33.3 & 0.86 & $0.00-9.04$ & 4 & 66.7 & 1.81 & $0.00-14.54$ & \\
\hline No temporary partner & 122 & 18 & 14.8 & - & - & 98 & 80.3 & - & - & \\
\hline \multicolumn{11}{|l|}{$\begin{array}{l}\text { Previous participation in } \\
\text { cervical cancer screening }\end{array}$} \\
\hline Yes & 96 & 14 & 14.8 & 1 & & 75 & 78.1 & 1 & & 0.24 \\
\hline No & 78 & 20 & 25.6 & 4.58 & $0.72-51.76$ & 56 & 71.8 & 2.27 & $0.41-23.32$ & \\
\hline
\end{tabular}

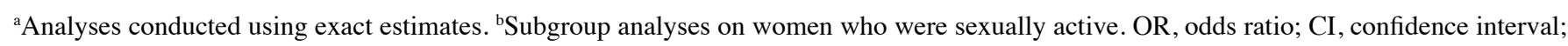
STI, sexually transmitted infection. Statistically significant OR and CI are marked in bold. 
Table IV. Multivariable analysis on acceptance of human papillomavirus (HPV) vaccination with 'unsure/unwilling even if vaccination was free' as reference category. ${ }^{\text {a }}$

\begin{tabular}{|c|c|c|c|c|c|}
\hline & \multicolumn{2}{|c|}{$\begin{array}{l}\text { Willing only if } \\
\text { vaccination } \\
\text { was free }\end{array}$} & \multicolumn{2}{|c|}{$\begin{array}{l}\text { Willing even if } \\
\text { vaccination } \\
\text { was not free }\end{array}$} & \multirow[b]{2}{*}{ p-value } \\
\hline & OR & $95 \% \mathrm{CI}$ & OR & $95 \% \mathrm{CI}$ & \\
\hline \multicolumn{6}{|c|}{ Believes vaccination to be a safe method to prevent disease } \\
\hline Very or fairly safe & 1 & & 1 & & 0.01 \\
\hline Not so safe or not safe & 0.07 & 0.01-0.49 & 0.15 & 0.03-0.88 & \\
\hline Don't know & 0.23 & $0.03-2.07$ & 0.05 & $0.01-0.51$ & \\
\hline \multicolumn{6}{|l|}{ Welfare recipient } \\
\hline No & 1 & & 1 & & 0.00 \\
\hline Yes & 0.53 & $0.05-5.38$ & 0.11 & 0.01-0.99 & \\
\hline \multicolumn{6}{|c|}{ Heard of condyloma (genital warts) prior to study ${ }^{\mathrm{b}}$} \\
\hline Yes & 1 & & 1 & & 0.0 \\
\hline No & 2.18 & $0.00-29.52$ & 0.27 & $0.00-1.94$ & \\
\hline
\end{tabular}

${ }^{a}$ All odds ratios are mutually adjusted for all other variables in the table. ${ }^{b}$ Analyses conducted using exact estimates. OR, odds ratio; CI, confidence interval. Statistically significant OR and CI are marked in bold.

The present study found that the overall theoretical acceptance of HPV vaccination was high, with $95 \%$ of women saying they were willing to be vaccinated against HPV. This overall figure was somewhat higher than those from a previous study from Argentina (16). Furthermore, the present study supplemented earlier material by investigating women's willingness to pay for vaccination, since national vaccination programs do not cover young adult women. Surprisingly, it was found that three out of four study women were willing to pay for HPV vaccination, despite their limited economic means.

The previous Argentinian study included 1,200 women from Buenos Aires and found that $75 \%$ were willing to have both themselves and their daughters vaccinated against HPV (16). One possible explanation for the higher acceptance proportion shown in our study is that information about HPV and its causative role in cervical cancer was provided before the women answered questions on acceptance. This highlights the importance of providing adequate information about vaccination. In addition, the previous study included women up to age 49 years, which may have affected the outcome (16). Indeed, several studies have observed that age has a negative correlation with acceptance of HPV vaccination $(17,18)$.

It was somewhat unexpected that as many as $75 \%$ of our study women were willing to be vaccinated even if vaccination was not free. Higher income was correlated with acceptance to pay for vaccination in the previous study in Sweden (17), but not in our study. Only $34 \%$ of women were willing to pay for vaccination in Sweden (17), highlighting the complexity of correlates of acceptance in relation to out-of-pocket payment for vaccination. The discrepancy may be due to differences in attitudes towards government expenditure and potentially the relative difference in cervical cancer burden, between these two populations. Nevertheless, the importance of an afford- able vaccine cannot be ignored. The highest median price that women in this study were willing to pay for HPV vaccination was 11.50 Euro per dose, far less than the actual cost, which is four times higher per dose (19). The fact that a mere $3 \%$ were willing to accept vaccination regardless of cost further underscores the importance of reasonable pricing. In the previous Argentinean study (16), cost was cited as the second most common reason for non-vaccination after lack of physician recommendation and several other studies have concluded the importance of costs in relation to vaccination acceptance $(17,18,20)$. Thus, the price of vaccination must be affordable in order to achieve high coverage among young adult women in Argentina.

The finding that an association exists between belief in vaccine safety/efficacy and acceptance is consistent with other studies $(17,20-22)$, though the correlation for belief in efficacy was not shown in the multivariable model. Being a welfare recipient and having prior awareness of genital warts have previously been reported to correlate positively with vaccination acceptance (17), but we are somewhat reluctant to interpret our findings on these matters, due to very wide confidence intervals. Neither could a correlation between acceptance of HPV vaccination and demographics, or sexual behavior be shown, though they have been discussed as possible correlates in several other studies $(17,18,20)$. Absence of these correlates could likely be explained by the limited sample size and homogeneity of the study population. Nevertheless, our data indicate that acceptance is highly influenced by general attitudes toward vaccination and that many respondents were unsure about the safety and effectiveness of vaccination, regardless of the type of vaccine. This, along with the finding that fear of adverse effects was a major reason for abstaining from HPV vaccination, suggests a need to further address the issue of the general 
Table V. Perceptions and concerns about human papillomavirus (HPV) vaccination.

$\mathrm{n}$

$\%$

\section{At what age do you think HPV}

vaccination should begin?

$0-11$

12-14

$15-17$

18 or older

Don't know

Do you believe you would be fully protected against cervical cancer if you were vaccinated against HPV?

Yes

No

Don't know

Do you believe you would be fully protected against condyloma (genital warts) if you were vaccinated against HPV?

Yes

No

Don't know

Would you consider having unsafe sex (i.e., not use a condom) more often than today if you were vaccinated against HPV?

Yes

No

Don't know

How would your participation in cervical cancer screening be affected if you were vaccinated against HPV? ${ }^{b}$

Would participate as previously

Less often than previously

Don't know

If you were vaccinated against HPV, do you believe you would participate in cervical screening in the future? ${ }^{c}$

Yes

No

Don't know

What information would you like to receive about the HPV vaccination? More than one alternative possible.

If the vaccine really offer protection

If the vaccine has side effects

If the vaccination has to be repeated

Other

I do not have any questions
Table V. Continued.

n

Which of the information above would make you abstain from HPV vaccine?

Only one answer.

If the vaccine really offer protection

$26 \quad 16.0$

If the vaccine has side effects

$89 \quad 54.6$

If the vaccination have to be repeated

15

9.2

Other

2.5

I would have the vaccination

regardless of questions

4

Don't know

18

11.0

11

6.7

${ }^{\text {aS }}$ Subgroup analysis among women who considered vaccination even if it was not free. ${ }^{b}$ Subgroup analysis among women who previously participated in cervical cancer screening. ${ }^{\mathrm{c}}$ Subgroup analysis among women who never heard of cervical cancer screening/had not participated in cervical cancer screening prior to study.

Table VI. Awareness of human papillomavirus (HPV)associated disease and screening practices.
46.6

17.2

36.2

\section{Heard of cervical cancer prior to study}

Yes

No

33

81

Heard of condyloma (genital warts)

prior to study

$$
9.8
$$

Yes

No

Heard of HPV prior to study

Yes

No

Heard of cervical cancer screening to

prevent cervical cancer

$\begin{array}{rr}23 & 24.0 \\ 1 & 1.0\end{array}$

Yes

No

Previously participated in cervical

cancer screening

Yes

No

Previous screening participation by age group:

18-19

Yes

No

20-25 
safety and effectiveness of vaccination. Additional research should address this topic in order to formulate a successful vaccination promotion strategy.

More than half the Argentinean women in this sample had heard of HPV, but few had heard of condyloma, another HPV-related disease. The fairly high level of HPV awareness may have been attributable to the current media campaign in connection with the launch of the HPV vaccination program against cervical cancer. Despite the high awareness of HPV it was clear that misconceptions exist about the protection conferred by HPV vaccination. Nearly half the respondents incorrectly believed they would be fully protected from cervical cancer, which is much higher than findings from European studies, where only 7-8\% believed HPV vaccine to offer complete protection $(17,23)$. Furthermore, one in 10 women stated they would consider using condoms less frequently if vaccinated. The fact that $24 \%$ of previous cervical cancer screening participants stated they would be screened less often if they were vaccinated further highlights extensive misconceptions. These findings imply an urgent need to develop a health education strategy in conjunction with the vaccination program.

Eighty-one percent of participants had heard of cervical cancer prior to the study, while $95 \%$ had heard of cervical cancer screening. One reason for this discrepancy could be that the commonly used name for cervical cancer screening is Papanicolaou, which is not related to the Argentinean word for cervical cancer, cancer de cuello uterino. Awareness of cervical cancer screening was equally high in an Argentinean study carried out in 2003 in which $93 \%$ of participants had heard of Pap smears (24) and $47 \%$ had participated in screening at some point - almost the same as the $55 \%$ in our study. However, our study participants were younger and when analyzing the distribution of screening participation by age, screening coverage (84\% of women aged 26-30) was clearly higher in the present study.

An important methodological issue in this study is the validity of the questionnaire. The questionnaire used in this study was adapted from a questionnaire used in a large Swedish population-based survey (17). However, some questions were multiple choice, while others were open-ended, which may have affected some responses. For example, a recurring spontaneous concern was high cost. It is probable that more participants would have expressed this as a major concern had that been explicitly included as a multiple-choice option. Also, the predictive validity concerning acceptance of vaccination if it was not free can be discussed, as this study investigated hypothetical willingness to be vaccinated when paying out of pocket and actual uptake may differ. In addition, the question on acceptance of vaccination if it was not free did not specify price, which may have been higher than respondents expected, which in turn could have potentially affected actual uptake. Moreover, the participants may have perceived that acceptance was the socially desirable response.

Some other limitations of this study need to be addressed. Firstly, the small sample size must be taken into account. Secondly, the potential for selection bias from several aspects must be considered: i) the limited geographical area represented with uptake from only one public hospital and ii) the important fact that all women actively sought health care.
Third, there was some level of non-participation that should be considered, although, even after excluding all written questionnaires, the participation rate still reached $76 \%$.

In conclusion, Argentinian women from a non-metropolitan setting showed a high acceptance of HPV vaccination both when free of charge and when out-of-pocket payment is required. This shows an important potential for disease prevention among women living in areas at high risk for cervical cancer. However, since perceived safety was found to be associated with HPV vaccination acceptance and since a considerable percentage of the women were unsure about vaccine safety, educational campaigns targeting these issues are needed. This study also suggests the need to address misconceptions about the protection conferred by HPV vaccination and to emphasize the necessity of continued participation in screening programs. Larger studies from Argentina are needed on this topic, both to corroborate the findings of this study and to investigate acceptance from a nationwide perspective.

\section{Acknowledgements}

We wish to thank Elisabeth Berg for statistical assistance, Trudy Perdrix-Thoma for editing assistance and Professor Pär Sparén for support and sharing of questionnaires. This study was supported by the Swedish Cancer Foundation (070623, CAN 2007/1044; 110544, CAN 2011/471), Karolinska Institutet Cancer Strategic Grants (5888/05-722), the Swedish Research Council (521-2008-2899), the Medical Research Council and the Cancer Society in Stockholm, the Stockholm County Council.

\section{References}

1. Ferlay J, Shin HR, Bray F, Forman D, Mathers C and Parkin DM: Estimates of worldwide burden of cancer in 2008: GLOBOCAN 2008. Int J Cancer 127: 2893-2917, 2010.

2. Bosch FX and de Sanjose S: Chapter 1: Human papillomavirus and cervical cancer - burden and assessment of causality. J Natl Cancer Inst Monogr: 3-13, 2003.

3. Munoz N: Human papillomavirus and cancer: the epidemiological evidence. J Clin Virol 19: 1-5, 2000.

4. Andrae B, Kemetli L, Sparen P, Silfverdal L, Strander B, Ryd W, et al: Screening-preventable cervical cancer risks: evidence from a nationwide audit in Sweden. J Natl Cancer Inst 100: 622-629, 2008.

5. Sankaranarayanan R: HPV vaccination: the promise and problems. Indian J Med Res 130: 322-326, 2009.

6. Centers for Disease Control and Prevention: Progress toward implementation of human papillomavirus vaccination - the Americas, 2006-2010. MMWR Morb Mortal Wkly Rep 60: 1382-1384, 2011.

7. Lu B, Kumar A, Castellsague $X$ and Giuliano AR: Efficacy and safety of prophylactic vaccines against cervical HPV infection and diseases among women: a systematic review and metaanalysis. BMC Infect Dis 11: 13, 2011.

8. Smith JS, Lindsay L, Hoots B, Keys J, Franceschi S, Winer R, et al: Human papillomavirus type distribution in invasive cervical cancer and high-grade cervical lesions: a meta-analysis update. Int J Cancer 121: 621-632, 2007.

9. Committee on Infectious Diseases: HPV vaccine recommendations. Pediatrics 129: 602-605, 2012.

10. Agurto I, Bishop A, Sanchez G, Betancourt Z and Robles S: Perceived barriers and benefits to cervical cancer screening in Latin America. Prev Med 39: 91-98, 2004.

11. Matos E, Loria D, Amestoy GM, Herrera L, Prince MA, Moreno J, et al: Prevalence of human papillomavirus infection among women in Concordia, Argentina: a population-based study. Sex Transm Dis 30: 593-599, 2003. 
12. Bruni L, Diaz M, Castellsague X, Ferrer E, Bosch FX and de Sanjose S: Cervical human papillomavirus prevalence in 5 continents: meta-analysis of 1 million women with normal cytological findings. J Infect Dis 202: 1789-1799, 2010.

13. 5th Global Meeting on Implementing, New and Under-utilized Vaccines, 22-24 June 2011 [Internet]. Geneva, Switzerland: New and Under-utilized Vaccines Implementation (NUVI) - World Health Organization (WHO); 2011 [updated 2011; cited 201120 Oct]. Available from: http://www.who.int/ nuvi/2011_meeting_summary_delivery-strategies/en/.

14. Vacuna contra el Virus del Papiloma Humano (VPH) [Internet]. Buenos Aires, Republica Argentina: Ministerio de Salud; 2013 [cited 201306 Mars]. Available from: http://www.msal.gov.ar/ index.php/programas-y-planes/185-vph.

15. Colantonio L, Gomez JA, Demarteau N, Standaert B, PichonRiviere A and Augustovski F: Cost-effectiveness analysis of a cervical cancer vaccine in five Latin American countries. Vaccine 27: 5519-5529, 2009.

16. Arrossi S, Maceira V, Paolino M and Sankaranarayanan R: Acceptability and uptake of HPV vaccine in Argentina before its inclusion in the immunization program: a population-based survey. Vaccine 30: 2467-2474, 2012.

17. Sundstrom K, Tran TN, Lundholm C, Young C, Sparen P and Dahlstrom LA: Acceptability of HPV vaccination among young adults aged 18-30 years - a population based survey in Sweden. Vaccine 28: 7492-7500, 2010

18. Black LL, Zimet GD, Short MB, Sturm L and Rosenthal SL: Literature review of human papillomavirus vaccine acceptability among women over 26 years. Vaccine 27: 1668-1673, 2009.
19. CDC Vaccine price list [Internet]. Atlanta, USA: Centers for Disease Control and Prevention; 2011 [updated 15 Dec 2011; cited 201129 Dec]. Available from: http://www.cdc.gov/vaccines/ programs/vfc/cdc-vac-price-list.htm.

20. Brewer NT and Fazekas KI: Predictors of HPV vaccine acceptability: a theory-informed, systematic review. Prev Med 45: 107-114, 2007.

21. Dahlstrom LA, Tran TN, Lundholm C, Young C, Sundstrom K and Sparen P: Attitudes to HPV vaccination among parents of children aged 12-15 years-a population-based survey in Sweden. Int J Cancer 126: 500-507, 2010.

22. Woodhall SC, Lehtinen M, Verho T, Huhtala H, Hokkanen M and Kosunen E: Anticipated acceptance of HPV vaccination at the baseline of implementation: a survey of parental and adolescent knowledge and attitudes in Finland. J Adolesc Health 40: 466-469, 2007.

23. Donders GG, Gabrovska M, Bellen G, Van Keirsbilck J, Van Den Bosch T, Riphagen I, et al: Knowledge of cervix cancer, human papilloma virus (HPV) and HPV vaccination at the moment of introduction of the vaccine in women in Belgium. Arch Gynecol Obstet 277: 291-198, 2008.

24. Gamarra CJ, Paz EP and Griep RH: Knowledge, attitudes and practice related to Papanicolaou smear test among Argentina's women. Rev Saude Publica 39: 270-276, 2005 (In Portuguese). 